\title{
The Correlation Between Cobb's Angle and Pedicle Rotation in Adolescent Idiopathic Scoliosis After Surgical Treatment
}

\author{
Danu Purnama Aji ${ }^{1}$, Christina Hari Nawangsih Prihharsanti ${ }^{2}$, Agus Priambodo ${ }^{3}$, Hermina \\ Sukmaningtyas ${ }^{2 *}$
}

${ }^{1}$ Faculty of Medicine, Diponegoro University, Semarang, Indonesia

${ }^{2}$ Departement of Radiology, Faculty of Medicine, Diponegoro University, Semarang, Indonesia

${ }^{3}$ Departement of Surgery, Faculty of Medicine, Diponegoro University, Semarang, Indonesia

Keywords:

Adolescent Idiopathic

Scoliosis,

Cobb's Angle,

Pedicle Rotation

*) Correspondence to:

hermina_rad@yahoo.co.id

Article history:

Received 28-11-2020

Accepted $08-12-2020$

Availableonline10-03-2021

\begin{abstract}
Background: Adolescent Idiopathic Scoliosis (AIS) is a 3-dimensional deformity that involves not only curve in the coronal and sagittal planes but also a rotation of vertebrae based on pedicle rotation. The Cobb's angle is the gold standard for measuring the lateral curve that could show the severity of the spine deformity. Cobb's method only evaluates the lateral curve, and the method to determine the pedicle rotation can be used in Nash and Moe's method. The higher pedicle rotation grade had a higher Cobb's angle. Surgical treatment for scoliosis is indicated for the curve exceeding $40^{\circ}$. Posterior spinal fusion is the most commonly used technique in scoliosis surgery.

Objective: To identify the correlation between Cobb's Angle and pedicle rotation in AIS after surgical treatment.

Methods: The research design used in this study was Cross-Sectional. The sample size of this study were 22 subjects using purposive sampling, the independent variable of this study was Cobb's angle while the dependent variable was pedicle rotation. Spearman's rank correlation was used to analyse the correlation between variables.

Results: The spearman's rank correlation revealed a significant correlation between the Cobb's Angle and pedicle rotation in AIS after surgical treatment with the $p 0,005$ and $r 0,462$.

Conclusion: This study demonstrates there is a significant correlation between Cobb's angle and pedicle rotation in AIS after surgical treatment with medium strength.
\end{abstract}

DIMJ, 2021, 2(1), 6-9 DOI: https:// doi.org/10.14710/dimj.v2i1.9531

\section{Introduction}

Adolescent idiopathic scoliosis (AIS) is a 3dimensional deformity that involves curve in the coronal and sagittal planes and also a rotation of the vertebrae. ${ }^{1}$ AIS is the most common type of scoliosis affecting $2-4 \%$ of adolescents in the world and it is diagnosed in children between 10 and 18 years of age. ${ }^{2}$

Several factors such as genetic, neuromuscular, growth, and developmental hypotheses can affect the incidence of the disease. However, at present, no single key factor has been identified. $^{3}$
The complication of scoliosis in some patients is back pain, cosmetic problem, physical disability, cardiopulmonary problem, and early mortality. ${ }^{4}$ These complications of scoliosis may affect the quality of life of the AIS patients. ${ }^{5}$ The X-ray imaging is the most commonly used in the diagnosis and assessment of scoliosis include standing AP or $\mathrm{PA}$ views, bending AP or PA views, and lateral views. ${ }^{4}$ The Cobb method is the most used method for determining the magnitude of the deformity of the spine and this method is a gold standard. ${ }^{6}$ 
Cobb's angle is an angle that can be found on the $\mathrm{AP}$ view by drawing a line parallel to the superior endplate of the top vertebra on the scoliosis curve and a line parallel to the inferior endplate of the bottom vertebra on the scoliosis curve. ${ }^{4}$ The limitations of the Cobb angle for describing vertebral rotation can be overcome by the NashMoe method. This method uses the pedicle location on frontal radiographs as an indicator of vertebral rotation..$^{7}$ Curves of less than $10^{\circ}$ are not considered to be scoliosis and curves more than $40^{\circ}$ require surgical treatment. ${ }^{6}$ Posterior spinal fusion is the most widely used technique in the surgical treatment of idiopathic scoliosis. ${ }^{8}$

\section{Method}

This study was conducted at the Radiology Department of Dr. Kariadi hospital, Semarang from July to August 2020. This study used a crosssectional study design. Purposive sampling was used as the sampling method. Inclusion criteria consist of AIS patient at Dr. Kariadi Hospital received operative therapy, the medical record data had a spinal X-ray AP view and the X-rays AP view are not damaged to determine Cobb's angle and pedicle rotation. While the exclusion criteria were having a history of trauma and tumor. The independent variable of this study was Cobb's angle. While the dependent variable of this study was pedicle rotation. Spearman's rank correlation was used to analyze the correlation between variables.

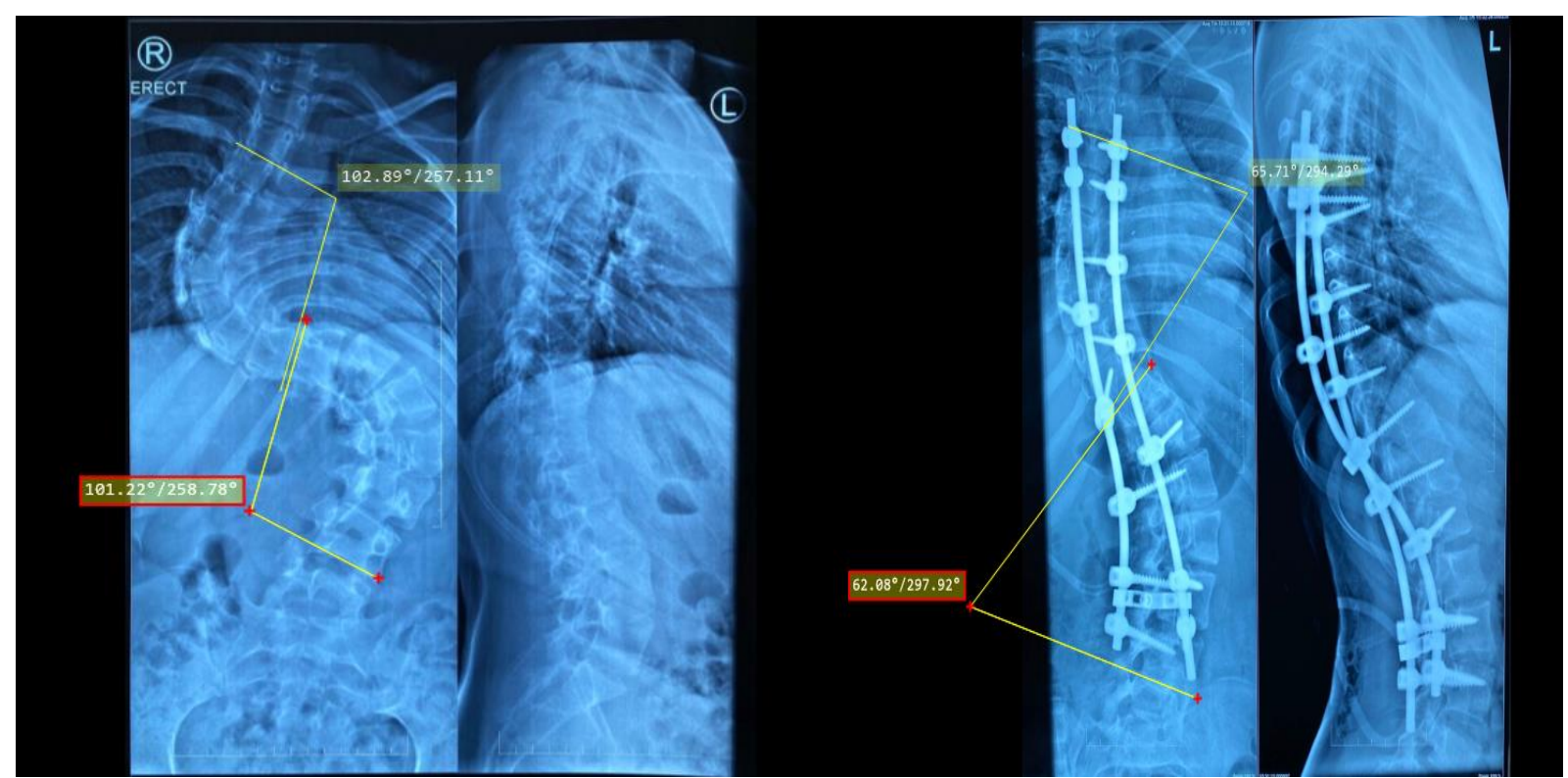

Fig.1 Digital radiograph measurement methods for a Cobb's angle

\section{Results}

A total of 22 patients ( 2 males and 20 females) were enrolled in this study from July to August 2020. The average age was 16 years old. The average Cobb's angle pre-surgery was $64,83^{\circ} \pm$ $26,51^{\circ}\left(29^{\circ}-121^{\circ}\right)$, and post-surgery was $32,47^{\circ} \pm$ $20,93^{\circ}\left(11^{\circ}-82^{\circ}\right)$. The biggest number of pedicle rotation pe-surgery was grade 2 and post-surgery was grade 1 . 
Table 1.Characteristic of Patients

\begin{tabular}{lcccc}
\hline \multicolumn{1}{c}{ Variable } & F & $\%$ & $\begin{array}{c}\text { Mean } \pm \\
\text { SD }\end{array}$ & $\begin{array}{c}\text { Median } \\
(\mathbf{m i n}- \\
\text { max })\end{array}$ \\
\hline Age & & & $16 \pm 3$ & $\begin{array}{c}15(12- \\
24)\end{array}$ \\
Gender & & & & \\
$\quad$ Male & 2 & 9,1 & & \\
$\quad$ Female & 20 & 90,9 & & \\
Cobb's Angle & & & $64,83^{\circ} \pm$ & $57^{\circ}\left(29^{\circ}\right.$ \\
pre & & & $26,51^{\circ}$ & $\left.-121^{\circ}\right)$ \\
Cobb's Angle & & & $32,47^{\circ} \pm$ & $26^{\circ}\left(11^{\circ}\right.$ \\
post & & & $20,93^{\circ}$ & $\left.-82^{\circ}\right)$ \\
Pedicle Rotation & & & & \\
pre & & & & \\
$\quad$ Grade 1 & 9 & 25,0 & & \\
$\quad$ Grade 2 & 20 & 55,6 & & \\
$\quad$ Grade 3 & 5 & 13,9 & & \\
$\quad$ Grade 4 & 2 & 5,6 & & \\
Pedicle Rotation & & & & \\
post & & & & \\
$\quad$ Grade 0 & 4 & 11,1 & \\
Grade 1 & 26 & 72,2 & & \\
Grade 2 & 5 & 13,9 & & \\
Grade 3 & 1 & 2,8 & & \\
\hline
\end{tabular}

Table 2.Correlation between Cobb's Angle and pedicle rotation

\begin{tabular}{|c|c|c|c|}
\hline & & $\begin{array}{l}P \\
\text { value }\end{array}$ & $\begin{array}{l}R \\
\text { value }\end{array}$ \\
\hline $\begin{array}{l}\text { Cobb's Angle Pre } \\
(\text { mean } \pm \text { SD) }\end{array}$ & $\begin{array}{l}64,83 \\
\pm \\
26,51\end{array}$ & 0,005 & 0,462 \\
\hline $\begin{array}{l}\text { Cobb's Angle Post } \\
(\text { mean } \pm \text { SD) }\end{array}$ & $\begin{array}{l}32,47 \\
\pm \\
20,93\end{array}$ & & \\
\hline Pedicle Rotation Pre & & & \\
\hline Grade 1 & 9 & & \\
\hline Grade 2 & 20 & & \\
\hline Grade 3 & 5 & & \\
\hline Grade 4 & 2 & & \\
\hline Pedicle Rotation Post & & & \\
\hline Grade 0 & 4 & & \\
\hline Grade 1 & 26 & & \\
\hline Grade 2 & 5 & & \\
\hline Grade 3 & 1 & & \\
\hline
\end{tabular}

\section{Discussion}

In this study, there were 2 male subjects or $9.1 \%$ and 20 female subjects or $90.9 \%$. In this study, the subjects of the study of AIS patients who underwent surgery were more women than men. The research findings are in line with the research of Suh et al. reveals that the prevalence of
AIS and progressivity of the scoliosis curve in women is higher than in men. ${ }^{9}$ The average age of the research subjects in this study was 16 years. The research results are consistent with the study of Kamtsiuris et al. showed that the prevalence of AIS was mostly found at the age of more than 15 years or after puberty. ${ }^{10}$

The 3-dimensional nature of scoliosis was well understood based on radiography..$^{11}$ The Cobb angle is the gold standard for measuring lateral curve that could show how severe the deformity of the spine. Nash-Moe method can be used to determine the rotational deformity of the vertebrae and this method is still widely used. ${ }^{11}$ The present study investigated the correlation between Cobb's angle and pedicle rotation in AIS after surgical treatment.

This study showed a significant correlation between Cobb's angle and pedicle rotation in AIS after surgical treatment. This study demonstrated that a higher pedicle rotation was correlated with a higher Cobb's angle. The results of this study are consistent with the findings of Mohanty et al that there was a correlation between Cobb's angle and Nash-Moe grades. ${ }^{11}$ In Easwar's study also found a correlation between Cobb's angle and vertebral rotation which was measured by Computed Tomography Scan (CT-Scan). ${ }^{12}$

The key factor affecting the progression of curve deformity in AIS are not fully understood. Various theories have been proposed concerning the development and progression of the rotational deformity in AIS. A study conducted by Lovett and Arkin proved that the combination of spinal deviation to the lateral and the axial rotation of the vertebrae in scoliosis is a normal characteristic of spinal kinematics. ${ }^{11}$ When the spinal curve begins to deform laterally it is followed by a rotation of the vertebrae. The ribs, which are attached to the vertebrae follow the rotational torque applied by the spine. ${ }^{13}$

The weakness of this research was not to consider other factors such as Body Mass Index (BMI), gender, physical activity, family history, and length of time the subject has scoliosis, which can affect the progression and severity of the scoliosis curve.

\section{Conclusion}

This study demonstrates there is a correlation between Cobb's angle and pedicle rotation in AIS after surgical treatment with medium strength. The higher pedicle rotation grade had a higher Cobb's angle and the lower pedicle rotation grade had a lower Cobb's angle. 


\section{Ethics Approval}

Ethical clearance was obtained from The Medical Research Ethical Committee of Faculty of Medicine Diponegoro University and Dr. Kariadi General Hospital Number 117/EC/ KEPK/FKUNDIP/VI/2020.

\section{Conflict of Interest}

None of the authors has any conflict of interest. This submission has not been published anywhere previously and that it is not simultaneously being considered for any other publication.

\section{References}

1. Lee CS, Hwang CJ, Jung HS, et al. Association Between Vertebral Rotation Pattern and Curve Morphology in Adolescent Idiopathic Scoliosis. World Neurosurg. 2020. doi:10.1016/j.wneu.2020.07.111

2. Kikanloo SR, Tarpada SP, Cho W. Etiology of adolescent idiopathic scoliosis: A literature review. Asian Spine J. 2019;13(3):519-526. doi:10.31616/asj.2018.0096

3. Zamecnik J, Krskova L, Hacek J, Stetkarova I, Krbec M. Etiopathogenesis of adolescent idiopathic scoliosis: Expression of melatonin receptors $1 \mathrm{~A} / 1 \mathrm{~B}$, calmodulin and estrogen receptor 2 in deep paravertebral muscles revisited. Mol Med Rep. 2016;14(6):57195724. doi:10.3892/mmr.2016.5927

4. A Gleiber M. Adolescent Idiopathic Scoliosis: An in Depth Analysis and Historical Review. MOJ Orthop Rheumatol. 2015;3(4). doi:10.15406/mojor.2015.03.00105

5. Lee H, Choi J, Hwang JH, Park JH. Healthrelated quality of life of adolescents conservatively treated for idiopathic scoliosis in Korea: A cross-sectional study. Scoliosis Spinal Disord. 2016;11(1):1-5. doi:10.1186/s13013-016-0071-1

6. Ritter R, Nagasse Y, Ribeiro I, Yamazato C, De Oliveira FM, Kusabara R. Comparison of Cobb angle measurement in scoliosis by residents and spine experts. Coluna/Columna. 2016;15(1):13-16. doi:10.1590/S1808185120161501147274

7. Kim H, Kim HS, Moon ES, et al. Scoliosis imaging: What Radiologists should know. Radiographics. 2010;30(7):1823-1842. doi:10.1148/rg.307105061

8. Kotwicki T, Chowanska J, Kinel E, Czaprowski D, Janusz P, Tomaszewski M. Optimal management of idiopathic scoliosis in adolescence. Adolesc Health Med Ther. 2013:59. doi:10.2147/ahmt.s32088

9. Suh SW, Modi HN, Yang JH, Hong JY. Idiopathic scoliosis in Korean schoolchildren: A prospective screening study of over 1 million children. Eur Spine J. 2011;20(7):1087-1094. doi:10.1007/s00586011-1695-8

10. Kamtsiuris P, Atzpodien K, Ellert U, Schlack R, Schlaud M. Prävalenz von somatischen Erkrankungen bei Kindern und Jugendlichen in Deutschland: Ergebnisse des Kinder- und Jugendgesundheitssurveys (KiGGS). Bundesgesundheitsblatt - Gesundheitsforsch Gesundheitsschutz. 2007;50(5-6):686-700. doi:10.1007/s00103-007-0230-x

11. Mohanty SP, Pai Kanhangad M, Gullia A. Curve severity and apical vertebral rotation and their association with curve flexibility in adolescent idiopathic scoliosis. Musculoskelet Surg. 2020;(0123456789). doi:10.1007/s12306-020-00660-0

12. Easwar TR, Hong JY, Yang JH, Suh SW, Modi HN. Does lateral vertebral translation correspond to Cobb angle and relate in the same way to axial vertebral rotation and rib hump index? A radiographic analysis on idiopathic scoliosis. Eur Spine J. 2011;20(7):1095-1105. doi:10.1007/s00586011-1702-0

13. Fadzan M, Bettany-Saltikov J. Etiological Theories of Adolescent Idiopathic Scoliosis: Past and Present. Open Orthop J. 2018;11(1):1466-1489. doi:10.2174/1874325001711011466 